\title{
REPLANTIO DA VEGETAÇÃO DO ECOSSISTEMA MANGUEZAL DO SACO DA FAZENDA, ITAJAÍ (SC)
}

\author{
TOGNELLA-DE-ROSA, M.M.P.'; OLIVEIRA, R.G.'; LUGLI, D.O. ${ }^{3}$ WILLRICH, J.F.;
} MEIRELES, R.P. \& T.V. POLETTO

\author{
Laboratório de Ecologia da Vegetação Costeira - CTTMar/Univali \\ 1'tognella@cttmar.univali.br, , ${ }^{2}$ rafago@ig.com.br, ${ }^{3}$ lugli@cttmar.univali.br
}

\begin{abstract}
RESUMO
O Saco da Fazenda apresenta um processo natural e recente de colonização de suas planícies de maré pelo ecossistema manguezal. Durante as dragagens ocorridas no Saco da Fazenda, o material grosseiro foi depositado nas suas margens, o que poderia comprometer o manguezal adjacente. Foi recomendado o replantio da vegetação. A técnica empregada foi o transporte das plantas. Para isso, foi realizada uma escavação ao redor do sistema de raízes e a árvore era imediatamente transportada para outro local. Nessa área foi aberta uma cova e a árvore replantada. Outro objetivo deste estudo foi a comparação entre a área replantada e o bosque natural, para isso fez-se necessário a delimitação de parcelas para obter o diâmetro, altura e densidade de indivíduos.
\end{abstract}

Palavras Chave: replantio, Laguncularia racemosa, Santa Catarina.

\section{MANGROVE REPLENISHMENT IN SACO DA FAZENDA, ITAJAÍ, SANTA CATARINA STATE}

\begin{abstract}
Saco da Fazenda is a meadow river abandoned, who is providing natural conditions to mangrove and salt marsh development. Since 1996 Saco da Fazenda has been drained and gross material has been deposited in his edge. This material influences mangrove ecosystem, than it was recommend his replenishment to adjacent area. The replenishment technique applied is plant transportation. It was made a narrow opening around the root system and the tree was transported to another place immediately. Another borrow was opening and the tree was replenished.Compeer replenishment experiment with structural characterization in preserved area was another scope by this research. Than some areas were delimited to know tree diameter, height and density.
\end{abstract}

Key words: replenishment, Laguncularia racemosa, Santa Catarina State.

\section{INTRODUÇÃO}

Esse presente estudo envolve as atividades realizadas durante o processo de replantio de vegetação do ecossistema manguezal que coloniza o Saco da Fazenda, Itajaí - SC, foi desenvolvido durante o segundo semestre de 2000 e tem sido objeto de monitoramento até o momento. Nesse ínterim, além das atividades necessárias ao replantio, foram executados outros estudos visando caracterizar a estrutura e composição de espécies no local, para melhor análise e interpretação da ecologia do manguezal e das conseqüências geradas pelo processo de replantio do mangue. 


\section{Área de estudo}

A área de estudo corresponde a um meandro abandonado situado na foz do Rio Itajaí-açú, que sofre grande assoreamento em virtude da circulação local e aporte de material proveniente do Ribeirão Schneider, cuja foz desemboca no interior do Saco da Fazenda, juntamente com várias outras fontes de efluentes de diversas origens.

Em virtude do assoreamento do Saco da Fazenda, está sendo realizada pela Cidasc a dragagem do material depositado no interior do ambiente. Esse material dragado de origem granulométrica mais grosseira foi depositado em dois locais situados na margem do Saco da Fazenda. Um deles localiza-se próximo a área da Marejada (bota-fora 01) e o outro (botafora 02) foi depositado nas proximidades do Saco da Fazenda com a Praia da Atalaia (Figura 1).

Nesta localidade, denominada de botafora 02, houve necessidade de replantio de algumas árvores de mangue (Laguncularia racemosa) para evitar o soterramento dos indivíduos.

\section{METODOLOGIA}

A metodologia aplicada ao replantio do manguezal do Saco da Fazenda (Itajaí,SC) encontra-se definida em etapas para melhor discussão dos resultados.

ETAPA 1: Levantamento da estrutura do manguezal localizado na região dos molhes onde está sendo realizado o bota-fora 02

As amostragens para caracterização do manguezal tiveram início no final de maio de 2000 e estendeu-se até agosto de 2000. Durante esse período foram realizadas diversas amostragens para estimar a densidade e diversidade de espécies que caracterizam o manguezal do Saco da Fazenda.
Para isso foram estabelecidas 11 parcelas amostrais de 1X1 metros para descrever a densidade de indivíduos. Esse tamanho amostral foi empregado em função da elevada densidade de indivíduos no local. Cada parcela teve todos os indivíduos presentes identificados, altura medida e o diâmetro a altura do peito (DAP) observado, seguindo metodologia de Schaeffer-Novelli \& Cintron (1986). A técnica de observação dos diâmetros das árvores foi adaptada em função da altura média dos indivíduos ser inferior a 1,0 metro na ocasião da amostragem. A fórmula empregada consiste na leitura do diâmetro na base do tronco para poder comparar todos os indivíduos e permitir o monitoramento do incremento em diâmetro e altura. As parcelas foram distribuídas aleatoriamente, de acordo com metodologia padronizada, no interior de todo bosque de mangue próximo ao bota-fora 02.

ETAPA 2: Delimitação da área de manguezal existente nas proximidades do bota-fora 02

Foram realizadas medidas para estimar superficialmente a área de manguezal presente nessa região (Figura 1). Para isso foi utilizada trena métrica determinando a área de um retângulo.

Nesse período foi realizada a delimitação da área de manguezal a ser transplantada, sendo demarcada com estacas.

\section{ETAPA 3: Replantio experimental de mangue}

No dias 20 e 21 de julho de 2000, junto com as atividades de caracterização estrutural, foram replantados quatro (04) indivíduos de mangue da espécie Laguncularia racemosa, única presente no bosque próximo ao bota-fora 02 . O pequeno número de indivíduos replantados teve objetivo de avaliar a viabilidade da técnica proposta.

A metodologia empregada consistiu na retirada de um torrão de sedimento com $30 \mathrm{~cm}$ de profundidade e diâmetro variando de acordo 
com a extensão do sistema de raízes, cujas árvores apresentavam alturas superiores a 1,50 metros. Cada um deles foi retirado e transportado individualmente para a área selecionada ao replantio. A retirada dos torrões empregou pá de cavar, procurando lesar o menos possível às raízes.

A seleção da área de replantio baseouse na análise de condições similares de fluxo dágua e período de inundação pela maré, evitando maior tensão sobre a vegetação, além daquela causada pelo replantio. Para isso foi selecionada uma área adjacente ao bosque, onde havia indícios fortes de expansão do manguezal para aquela região. Esse local já mostrava intenso assoreamento e início de colonização por indivíduos de Spartina sp, indicando condições ideais para a colonização de mangue.

As árvores foram transportadas dentro de monoblocos até o local de replantio. Nesse local, uma equipe já estava abrindo as covas com enxadas para colocar os torrões, evitando maior exposição das raízes.

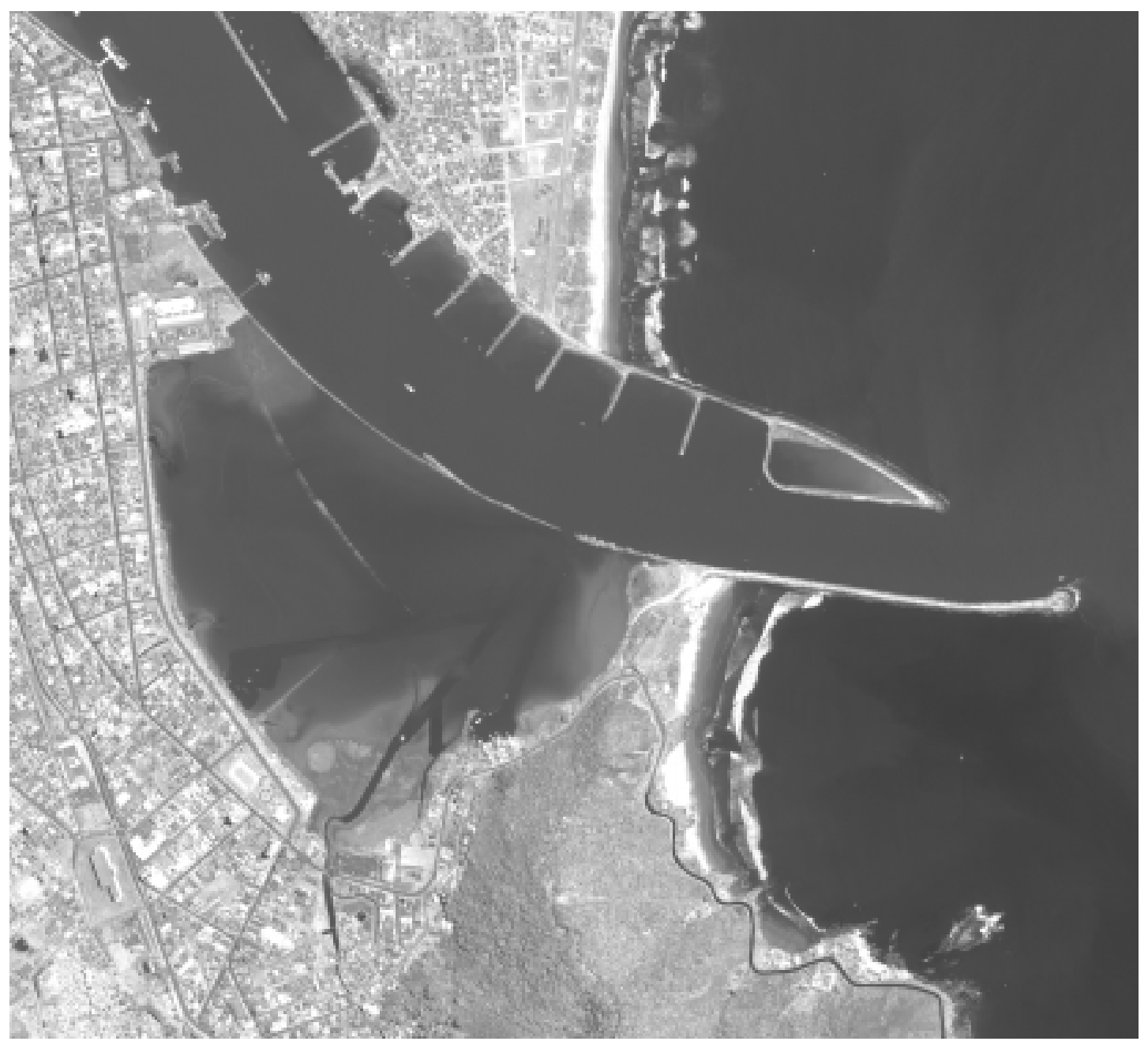

Figura 1: Área de estudo, com descrição dos locais de bota-fora. 
As árvores coletadas para o replantio experimental foram monitoradas semanalmente durante os meses de agosto, setembro, outubro de 2000, juntamente com o processo de replantio. A partir do mês de novembro de 2000, os indivíduos que sobreviveram foram monitorados em conjunto com as demais árvores replantadas, mensalmente.

Os indivíduos selecionados para essa etapa foram escolhidos entre os mais altos na porção do bosque que seriam replantadas. Apresentavam alturas de 1,30, 1,50, 1,80 e 2,00 metros.

Nessa etapa também foi realizada a caracterização da vegetação colonizadora da foz do Ribeirão Schneider. As amostragens da vegetação local constataram presença de vegetação de marisma e manguezal. Nessa região domina o ecossistema marisma, o qual ocorre na área com cinco espécies ainda não identificadas.

Nessa área, além da visualização das condições locais e realização de fotografias, foi determinada uma parcela para estimar a estrutura da vegetação de mangue.

\section{ETAPA 4: Replantio de mangue}

Nos meses de agosto, setembro e outubro, foi realizado o replantio de 134 indivíduos de mangue e o monitoramento dos indivíduos (04) replantados em julho, onde foram observados a condições gerais da árvore referente ao número de folhas e estado do caule e raízes. Sendo que neste monitoramento observou-se uma taxa de sobrevivência de $50 \%$.

Em função da experiência anterior, observou-se a necessidade de aumentar a profundidade das covas para proporcionar maior estabilidade ao indivíduo replantado. Além disso, as árvores foram plantadas mais próximas procurando amenizar o impacto causado pela ação de ondas e marés.
A equipe de trabalho foi dividida em três grupos: retirada da vegetação, transporte e replantio. Isso permitiu agilizar a realização do trabalho, evitando maior exposição do sistema radicial ao ar.

As árvores não foram retiradas dentro das coortes de idade, em função da dificuldade de isolar os indivíduos por classe de tamanho durante os trabalhos de campo.

A metodologia de transplante procurou evitar ao máximo a lesão do sistema radicial das árvores, tendo sido transplantados desde propágulos, associados a indivíduos maiores, até árvores com aproximadamente 2,00 metros de altura.

As árvores só puderam ser transplantadas nas marés de sizígia, por ocasião de maré baixa, o que dificultou e diminuiu o ritmo do replantio. Por ocasião de cada saída de campo, foram transplantadas, em média, 25 árvores. Em alguns casos, as árvores tiveram seus torrões recobertos com mais sedimento. Isso foi realizado sempre que as raízes ficavam expostas e quando a árvore parecia não apresentar tanta estabilidade.

\section{ETAPA 5: Replantio maciço de manguezal}

Essa etapa foi realizada durante o período de 26 a 30 de dezembro de 2000.

Devido ao aumento da densidade de indivíduos e aumento no porte das árvores, localizadas mais internamente no bosque, foi necessário a contratação de sete homens que auxiliaram os técnicos na retirada, transplantes e replantio das mesmas. A técnica de replantio foi a similar a empregada em todo o processo descrito até o momento.

O processo de replantio foi acelerado porque a região do bota-fora 02 já estaria sendo utilizada como área de despejo. Com objetivo de evitar possíveis danos, o processo de replantio foi acelerado, procurando deixar uma área ao redor do bota-fora livre de vegetação. 


\section{RESULTADOS E DISCUSSÃO}

ETAPA 1: Levantamento da estrutura do manguezal localizado na região dos molhes onde está sendo realizado o bota-fora 02

Durante as amostragens observou-se que realmente Laguncularia racemosa é a única espécie de mangue presente no local.

Analisando os resultados amostrados nas parcelas, observou-se que o bosque apresenta uma altura média de 2,00 metros. Sendo que o maior indivíduo observado apresentou 4,00 metros de altura, estando localizado no interior do bosque onde teve início o processo de colonização do manguezal nessa região.

O número de indivíduos por metro quadrado variou de 1 até 15 , determinando um número médio de 7 indivíduos por metro quadrado. Foram amostrados 78 indivíduos nas 11 parcelas, alguns contendo vários troncos.

Analisando as parcelas de forma segmentada, esse número médio de indivíduos por metro quadrado diminui na área onde foram retiradas as árvores de mangue, bem como a altura média que passa para 1,5 metros. Nessas parcelas obteve-se um número médio de 4 indivíduos por metro quadrado.

É fácil explicar a causa da diminuição da densidade e estatura neste local do bosque de mangue, sabendo-se que a região estudada é protegida por uma berma e o aporte de água e propágulos provenientes da maré atingem essa região pela porção interna, após atravessar todo o bosque. Nesse local registra-se a presença de Hibiscus sp., típico de áreas menos inundadas, de invasoras terrestres e também o menor porte da vegetação do manguezal.

A classe de DAP predominante foi a de indivíduos menores que $2,5 \mathrm{~cm}$, representada por 61 árvores (78\%). Isso caracteriza um bosque extremamente juvenil, apesar de alguns indivíduos apresentarem mais elevada estatura.

Os demais indivíduos (22\% do total) caracterizam a classe de DAP maior e igual a
$2,5 \mathrm{~cm}$ e menor e igual a $10,0 \mathrm{~cm}$, sendo justamente estes que apresentam alturas superiores a 2,00 metros. Esses indivíduos representam o recrutamento inicial do bosque.

Foi quantificada também a densidade de propágulos nas parcelas, variando de ausentes até 100 registros por metro quadrado. Esse resultado, juntamente com a classe de DAP predominante, comprova que o bosque é relativamente jovem.

A abundância de aporte de propágulos irá contribuir para a manutenção do bosque remanescente e incremento de indivíduos na área replantada.

ETAPA 2: Delimitação da área de manguezal existente nas proximidades do bota-fora 02

De forma bastante empírica foi definida a área de mangue a ser retirada e transplantada, resultando em 800 metros quadrados. Essa área foi determinada somente para definir o número de indivíduos que seriam replantados.

Com base nas parcelas realizadas nessa área estimou-se que o replantio seria entre 1000 a 1500 indivíduos. Este número foi estabelecido empregando-se a área e variação de densidade de indivíduos por metro quadrado (1 até 11 árvores) observada nos bosques adjacentes.

\section{ETAPA 3: Replantio experimental de mangue}

O primeiro sinal observado nesses indivíduos caracterizando o estresse pelo qual as árvores haviam passado foi a mudança de coloração das folhas. As folhas ficaram amareladas e em dois indivíduos (com altura de 1,30 e 2,00 metros), logo após o replantio (30 dias), perderam todas as folhas. Os outros dois indivíduos restantes (com altura de 1,50 e 1,80 metros) demoraram mais a perder suas folhas que ficaram bastante tempo secas nos ramos.

O estresse da exposição das raízes, mesmo que temporário, associado à mudança da energia hidráulica a qual o indivíduo estava sujeito pode ter sido acentuado pelas baixas 
temperaturas. Infelizmente, não houve condições de estabelecer um anteparo que pudesse atenuar a energia de ondas e marés que chega até a área de replantio.

No final do mês de setembro, as duas árvores que permaneceram mais tempo com as folhas, começaram a apresentar rebrotamento de suas folhas, não em grande densidade, mas indicando que o indivíduo procurava se restabelecer.

No mês de outubro, considerou-se que aquelas que não haviam rebrotado estavam definitivamente mortas, pela análise do caule observou-se que as chances de recuperação eram remotas.

Nos monitoramentos realizados nos meses de novembro e dezembro de 2000 e em janeiro e fevereiro de 2001, os dois indivíduos continuavam apresentando aumento na densidade de folhas.

Inicialmente, quando o número de indivíduos a serem monitorados era pequeno realizava-se a contagem das folhas, classificandoas em vivas, amarelas e secas. Posteriormente, após outubro, esse tipo de atividade tornouse inviável.

Considerando o número de indivíduos replantados experimentalmente, a taxa de sobrevivência foi de $50 \%$, um índice bastante alto perto do observado em outros estudos de replantio de mangue. Os experimentos que reportam replantio de árvores de maior porte são bastante reduzidos, com pequeno número de indivíduos também, e com taxas de sobrevivência menores ao observado.

O que pode ter contribuído com a taxa de sobrevivência observada é o fato das árvores terem sido replantadas no mesmo dia e em locais similares ao original em termos de salinidade, mudando somente a dinâmica. Geralmente, os experimentos relatados na literatura tratam de replantios de indivíduos para áreas distintas ou que passaram um determinado período em estufas.

Durante o desenvolvimento dessa etapa, foi solicitada uma avaliação da estrutura do manguezal ao longo da foz do Ribeirão Scheneider.

A vegetação que ocorre nas margens do Ribeirão Schneider é constituída de espécies típicas das marismas e do manguezal. Há predomínio de indivíduos vegetais características das marismas, ocorrendo quatro gêneros: Paspalum sp., Typha sp., Scirpus sp. e outro gênero pertencente a família das Cyperaceae. São bastante densas em ocupação do substrato e encontram-se distribuídas em manchas de acordo com suas preferências em substrato e freqüência de inundação.

Os indivíduos de mangue que colonizam a área em manchas esparsas são das espécies Laguncularia racemosa e Rhizophora mangle. Considerando a margem esquerda do ribeirão, podem ser encontradas pelo menos oito manchas com mangue. As menores apresentam dimensão de $80 \mathrm{~m}^{2}$, com indivíduos apresentando altura média de 4 metros. Pelo tempo de colonização dessa área pela vegetação de mangue e associados às condições ambientais, esses indivíduos apresentam-se bastante ramificados podendo ter até 11 troncos.

\section{ETAPA 5: Replantio maciço de manguezal}

Essa etapa foi realizada no final de dezembro de 2000 e neste momento foi iniciado o monitoramento das mesmas. Devido à densidade de indivíduos foram comprados lacres numerados para realizar a marcação das árvores, com isso foi possível identificar cada indivíduo e suas alterações.

Isso não foi feito anteriormente pelo número reduzido de árvores que permitia um acompanhamento individual por etapa de replantio e fileira de indivíduos.

De posse dos lacres, todos os indivíduos replantados foram marcados e estão sendo monitorados aleatoriamente.

O conhecimento gerado pelas duas etapas anteriores de replantio permitiu identificar 
que um prazo de dois meses entre cada avaliação é compatível.

\section{AGRADECIMENTOS}

Os autores agradecem aos funcionários Valdenir Manoel Inez, João de Jesus Severino e Rodrigo Jair da Silva pela ajuda durante o processo de replantio.

\section{REFERÊNCIA BIBLIOGRÁFICA}

Schaeffer-Novelli, Y. \& G. Cintron. 1986. Guia para estudo de áreas de manguezal, estrutura, função e flora. Caribbean Ecological Research. São Paulo, 150 p. 